\title{
Afrika Kütüphane Projesi
}

\section{African Library Project}

\section{Demet Soylu* (iD) ve Tunç D. Medeni**iti}

\section{$\ddot{O} z$}

Bu okuyucu mektubu Afrika Kütüphane Projesi'nin nasıl hayata geçirildiğini ortaya koymayı ve proje hakkında bilgi vermeyi amaçlamaktadır.

Anahtar Sözcükler: Afrika; Afrika kütüphane projesi; Chris Bradshaw.

\begin{abstract}
This reader letter aims to put forward how African Library Project was carried out and provide information about the project.
\end{abstract}

Keywords: Africa; African library project; Chris Bradshaw.

\section{Giriş}

Dünyada kütüphanecilik alanındaki örnek girişimlerden biri de Afrika Kütüphane Projesi olup proje 2005 y1lında Chris Bradshaw tarafından hayata geçirilmiştir. Afrika'daki düşük okuryazarlık düzeyini artırmayı hedefleyen proje farklı kurum ve kuruluşlar tarafından desteklenmektedir. Botswana Cumhuriyeti Milli Eğitim Bakanlığı, Micheal Lapsley Sivil Toplum Kuruluşu (Gana), Rongo Üniversitesi ve Kibabii Üniversitesi (Kenya), Lesotho Milli Eğitim Bakanlığı, Amerika Birleşik Devletleri Lesotho Barış Gönüllüleri, DAPP (Halktan Halka Gelişim Desteği Kuruluşu, Malawi), Wungwero Kitap Vakfı (Malawi), Malawi Eğitim Enstitüsü, Malawi Üniversitesi, RISE (Okuma Girişimi) Çalışma Ağı, Enjuba Eğitim Kuruluşu (Uganda), Firm Foundation Education Trust (Uganda) proje ortakları arasındadır (African Library Project, 2021). Proje kapsamında, kitaplara erişim imkânı bulunmayan bölgelerde kütüphaneler kurulmakta ve kitaplar halka ulaştırılmaktadır.

\footnotetext{
* Ankara Yıldırım Beyazıt Üniversitesi, Bilgi ve Belge Yönetimi Bölümü. Ankara, Türkiye. E-posta: bunchnoble@gmail.com

Ankara Yıldırım Beyazıt University, Department of Information Management. Ankara, Turkey. E-Mail: bunchnoble@gmail.com.

** Ankara Yıldırım Beyazıt Üniversitesi, Yönetim Bilişim Sistemleri Bölümü, Ankara, Türkiye. E-Posta: tuncmedeni@gmail.com

Ankara Yıldırım Beyazıt University, Department of Management Information Systems, Ankara, Turkey. E-Mail: tuncmedeni@gmail.com
}

Geliş Tarihi-Received: 04.09.2021

Kabul Tarihi - Accepted: 20.09.2021

Yayımlanma Tarihi-Published: 30.09.2021 
Projenin başlangıç hikâyesi çok ilginç olmakla birlikte insanın hayallerinden asla vazgeçmemesi gerektiği gerçeğini de gözler önüne sermektedir. İnsanın içindeki heves ve tutku bitmedikçe hayaller yıllar sonra da gerçekleşebilir. İşte bu projenin ortaya çıkması Chris Bradshaw'un içinde kalan tutku sayesindedir. ${ }^{1}$

Chris Bradshaw, Afrika Kütüphane Projesinin lideri ve kurucusudur. Bu projenin temellerini yıllar önce Afrika'da atmıştır. 1971-1975 yılları arasında Amerika Birleşik Devletleri'ndeki Denison Üniversitesi'nde Afrika Dili ve Edebiyatı bölümünde lisans öğrencisi olarak öğrenim görmüştür. 1973-1974 yıllarında da ziyaretçi öğrenci olarak Afrika'da yaşamış ve bulunduğu dönemde Afrika kültürünü ve geleneklerini dikkatli bir şsekilde gözlemleme firsatını yakalamıştır. Üniversite eğitiminin üçüncü yılını Sierra Leone Üniversitesi'ne bağlı Fourah Bay Meslek Yüksek Okulunda geçirdiği zamandan beri Afrika ile ilişki içinde olmuştur. Ziyaret ettiği yerel topluluklara yardımcı olmak istemişse de o yıllarda yapacağı iş konusunda emin olamamış ancak yıllar sonra "Bilgiye hiçbir şekilde erişim şansı olmayan çocuklara bilgi dünyasının kapılarını açmak istedim. Okuryazarlı̆̆ın gelişimin önemli bir parçası olduğunun farkındaydım. Başlangıçta aklımda bir kütüphane fikri vardı fakat kitapseverlerin müthiş coşkusunu fark ettiğimde ben de fark yaratmak istedim" düşünceleriyle Afrika Kütüphane Projesini hayata geçirme kararı almıştır.

Bradshaw, Afrika dini, edebiyatı ve hukuku konusunda çalışmış olup üniversitede eğitim gördüğü yıllarda Batı ve Orta Afrika’ya çeşitli seyahatler gerçekleştirmiştir. Yolculukları sırasında Afrikalıların cömertliğinden ve zorluklarla başa çıkabilme becerisinden olağanüstü etkilenmiştir. Görevi bittiğinde dahi Afrika için somut bir şeyler yapma konusundaki tutkusunun hala bitmediğini fark etmiştir.

Bradshaw 2004'te, otuz bir y1l sonra ailesiyle birlikte Kuzey Afrika seyahati esnasında Lesotho'da ata binmeye gittiklerinde: "Bir gün oğlum ata binmekten sıkıldı ve kitap okumaya başladı. Bu noktada kütüphaneyi anımsadım. At yolculuğum boyunca ülke geneline ait bir kütüphanenin olma fikri aklımdan hiç çıkmadı hem de Amerika'da sayıca fazla olan kitaplar bir sorun haline gelmişken. At gezintisinin başlangıç noktası olan köye döndüğ̈̈̈müzde sorumlu kişi bana bir kütüphaneye sahip olmak istediklerini fakat kitaplart nasıl temin edeceklerini bilmediklerini söyledi. Lesotho'da kitap satın alınabilecek hiçbir yer yoktu ve Kuzey Afrika civarındaki yerlerde de kitaplar fahis fiyatlarla satılıyordu."

Bradshaw ülkesine dönüp yeniden çalışmaya başladığında, kâr amacı gütmeyen faaliyetlerdeki geçmiş deneyimlerine de dayanarak ilk aşamada kitapları toplayıp kargolamaya başlamış fakat sonradan bunun tek başına üstesinden gelebileceği bir iş olmadı̆̆ının farkına varmıştır. Daha sonra süreci desteklemeleri için yereldeki okullarla temasa geçmiş ve okulların gönüllü olarak yardımcı olma tutkusunu gördüğünde çok mutlu olmuştur. $\mathrm{Bu}$ aşamada Bradshaw, Afrika Kütüphane Projesinin oluşturulmasına yardımcı olan bir topluluk kurmayı başarmış ve birçok kişi bu sosyal sorumluluk projesinin parçası olmuştur. Örneğin teknoloji kurdu bir arkadaşı web sitesi kurmayı önermiş, on altı yaşındaki oğlu Ben ise kâr amacı gütmeyen kurumsal bir profile sahip olunması için başvuruyu hazırlamıştır. Ayrıca Gambia'daki görevi süresince iki kütüphane kurup sonrasında başarısız olan Barış Gönüllüsü arkadaşı Sarah Stapleton izlenecek politikalar konusunda yardımcı olmuştur. Bunun yanı sıra

1 Bu projenin hikâyesi https://www.africanlibraryproject.org/past-chris-bradshaw/ sitesindeki bilgilerden yararlanılarak İngilizceden Türkçeye çevrilmiş̧ir. 
finans, kütüphane geliştirme, teknoloji konularında uzman olan kişiler de sürece müdahil olmuştur. Bu girişimlerin ardından ilk kütüphane Lesotho'da Malealea Vadisindeki halka ait olan bir kulübe şeklinde kurulmuştur (Bkz. Görsel 1). Kütüphaneciler ve halkın tanıklığında aynı sene beş kütüphane daha kurulmuştur.

\section{Görsel 1}

\section{Proje kapsaminda kurulan ilk kütüphane}

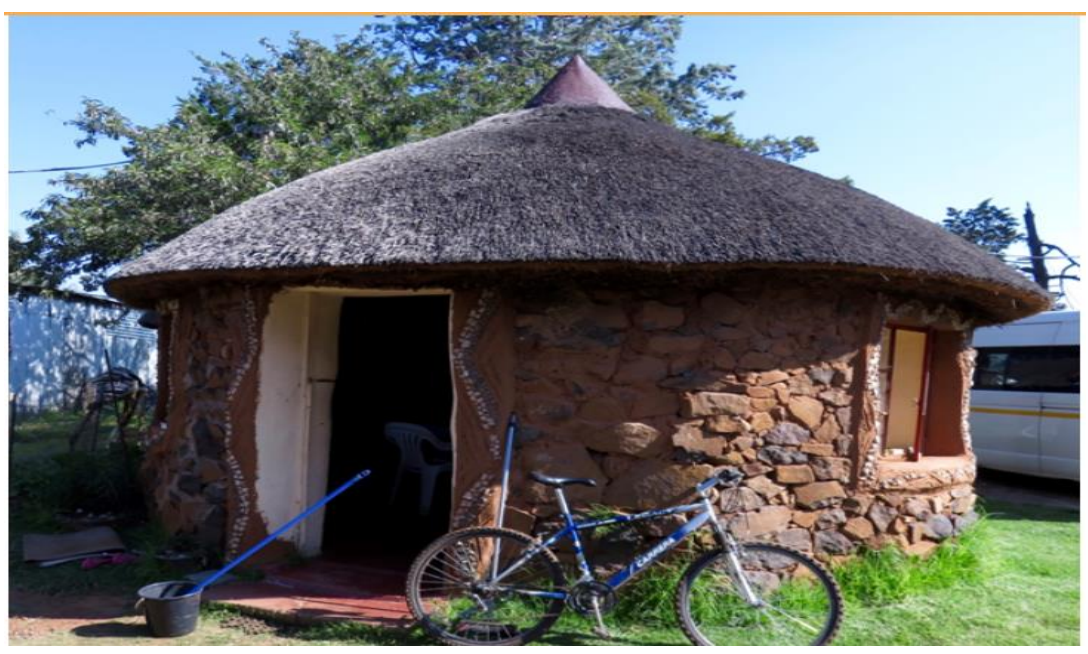

Not. (African Library Project, 2020). ${ }^{2}$

\section{Görsel 2}

\section{Chris Bradshaw}

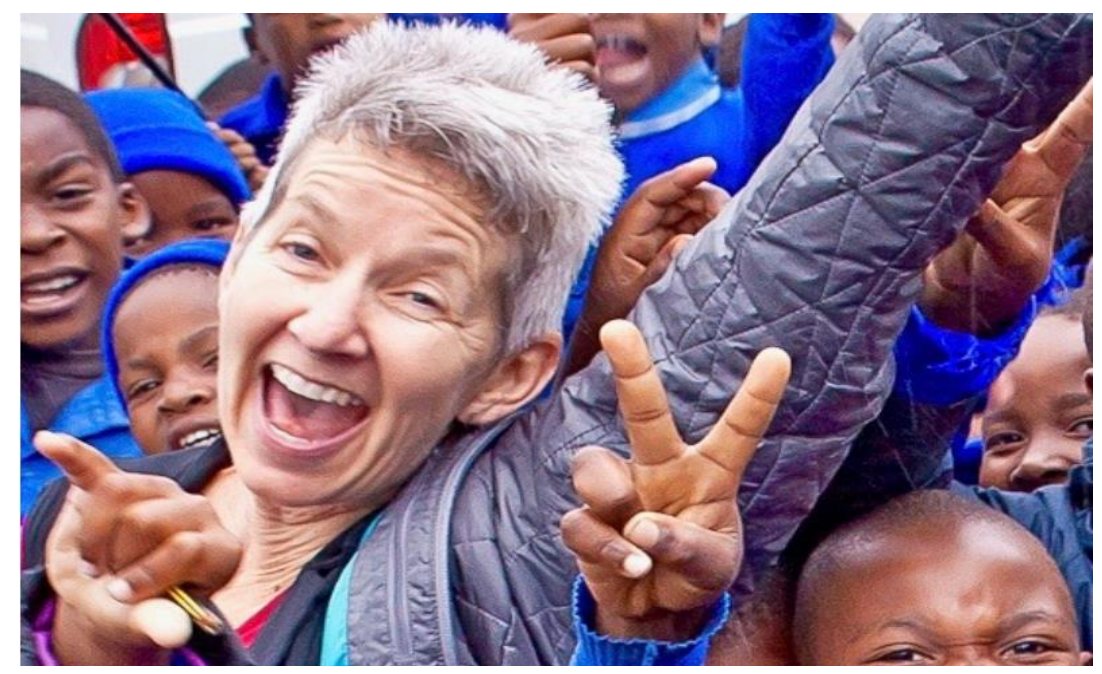

Not. (African Library Project, 2020). ${ }^{3}$

Bradshaw'un yıllar sonra gerçekleştirdiği hayal Afrika açısından müthiş bir açılımın ortaya çıkmasını sağlamıştır. Proje kapsamında yılda 30-60 civarında kütüphanenin kalkınmasına destekte bulunulmakta, kitap temini proje ortakları tarafından sürdürülmekte ve Afrika'da yeni hayatlara dokunulmaya devam edilmektedir.

\footnotetext{
${ }^{2}$ Bu görselin kullanımı için Afrika Kütüphane Projesi koordinatörlüğünden gerekli izinler alınmıştır.

${ }^{3}$ Bu görselin kullanımı için Afrika Kütüphane Projesi koordinatörlüğünden gerekli izinler alınmıştır.
} 
Gittikçe gelişen ve geliştiren bu projenin emsallerini görmeyi umarak Chris Bradshaw'un gurur verici davranışını bir kez daha takdir ediyoruz. Hayallerini gerçekleştirme tutkusu içindeki yeni liderleri görme dileklerimizle...

\section{Kaynakça}

African Library Project. (2020). The first African Project Library. https://www.africanlibraryproject.org/past-chris-bradshaw/

African Library Project. (2021). Our partners. https://www.africanlibraryproject.org/our-partners/ 